\title{
A Review on Smoking is Injurious to Health
}

\author{
Ravichandran $\mathrm{S}^{1}$, E. Prabhakar Reddy ${ }^{2 *}$, Aravind $\mathrm{C}^{3}$
}

${ }^{1}$ Associate Professor of Biochemistry, ${ }^{2}$ Professor of Biochemistry and Central Lab Head, ${ }^{3}$ Professor of General Medicine, Sri Lakshmi Naryana Institute of Medical Sciences, Puducherry, Bharath University

DOI: $10.36348 /$ sijb.2020.v03i07.002 $\quad$ | Received: 28.06 .2020 | Accepted: 06.07.2020 | Published: 08.07 .2020

*Corresponding author: E. Prabhakar Reddy

\section{Abstract}

Tobacco smoke contains numerous compounds, the important substances of medical significance being the carcinogens (such as polycyclic aromatic hydrocarbons), irritant substances, nicotine, carbon monoxide and other gases. Cigerette smoking is a well-known major risk factor for premature mortality due to cancer, cardiovascular disease, and chronic obstructive pulmonary disease. There is also evidence that passive smoking may contribute to atherosclerosis by sensitizing neutrophils, causing their activation and subsequent oxidant-mediated tissue damage. To achieve a meaningful reduction in the burden to society of coronary heart disease, both passive and active cigarette smoking must be targeted. Many children are regularly exposed to cigarette smoke at home or in other environments, such as child-care facilities and schools. The only safe way to protect nonsmokers from exposure to cigarette smoke is to eliminate this health hazard from public places and workplaces, as well as from the home.

Keywords: Carcinogens, Carbon monoxide, Nonsmokers, Cancer, Tobacco.

Copyright @ 2020: This is an open-access article distributed under the terms of the Creative Commons Attribution license which permits unrestricted use, distribution, and reproduction in any medium for non-commercial use (NonCommercial, or CC-BY-NC) provided the original author and source are credited.

\section{INTRODUCTION}

Responsible for approximately 100 million deaths in the past century and 5.4 million in 2005 alone, there are still an estimated 1.3 billion smokers in the world. Currently, smoking prevalence has decreased in the United States and some other countries but has increased in less-developed world regions [1].

In the lung, where there is intimate exposure to inhaled tobacco smoke, about $80 \%$ of all primary cancers are attributable to smoking [2]. Smoking related cancers are also frequent in the oropharynx and larynx, where there is direct contact with tobacco-related carcinogens. Smoking also increases the risk of cancer in organs such as the kidney, bladder, cervix, lower urinary tract, and pancreas, organs for which exposure to tobacco degradation products is indirect [3]. With respect to the digestive tract, esophageal and gastric cancers have been strongly associated with tobacco, whereas the smoking colorectal cancer (CRC) link remains controversial. Several large cohort studies linked smoking with CRC [4-6].

Tobacco smoke contains numerous compounds, the important substances of medical significance being the carcinogens (such as polycyclic aromatic hydrocarbons), irritant substances, nicotine, carbon monoxide and other gases [7]. Smoking has an affect on the various metabolic and biological processes in the body including secretion of hormones. These are mediated chiefly through behavioural and pharmacological actions of nicotine but also occur as a result of increases in the physical effects of stress on the body caused by smoking. In normal men, smoking causes an increase in heart rate and blood pressure as a result of constriction of blood vessels. It tends to increase the concentration of fatty acids in the blood and also the liability of blood platelets to adhere to each other and to the walls of blood vessels. Nicotine also causes stimulation and sedation of the central nervous system depending upon the dose. Carbon monoxide in tobacco smoke has a higher affinity for haemoglobin, thereby reducing the oxygen-carrying capacity of the blood. The aim of this review is to describe the effects of smoking on the various hormones with its clinical consequences and to discuss the association of smoking with endocrine diseases.

Even in males, smokers have a lower bone mineral density as compared with non-smokers [7, 8]. Insulin resistance is also more common in smokers and may contribute to the increased incidence of cardiovascular disease. More pronounced responses are seen in heavy smokers as compared with light smokers reflecting the direct toxicogenic effect of cigarette 
smoke. Maternal smoking affects the infants in a similar way to adults. It is also possible that passive smoking could also affect the growth of young children through decrease in $\mathrm{GH}$, as seen in chronic smokers.

\section{DISCUSSION}

Cigerette smoking is a well-known major risk factor for premature mortality due to cancer, cardiovascular disease, and chronic obstructive pulmonary disease. Cigarette smoking also appears to be a major risk factor for respiratory tract and other systemic infections. Both active and passive cigarette smoke exposure increase the risk of infections. The morbidity and mortality of infectious diseases due to smoking are not widely appreciated by physicians. 'The main cause of non-small cell lung cancer (NSCLC) is cigarette smoke (CS). It has been hypothesized that CS induces carcinogenesis mainly by an oxidant-mediated mechanism. CS contains high levels of oxidants and oxidant-generating compounds. It increases oxidant generation by inflammatory and non-phagocytic cells [9], it contributes to the persistence of chronic inflammation, and it modulates tissue antioxidant capacity [10]. An excess of reactive oxygen species (ROS) can cause multiple alterations in cellular molecules [11], which in turn alter cells' permanent growth arrest, apoptosis [12], and angiogenesis [13]. ROS have been connected with carcinogenesis in a number of different malignancies [11].

Cigarette smoking is a well-known major risk factor for premature mortality due to cancer, cardiovascular disease, and chronic obstructive pulmonary disease. Cigarette smoking also appears to be a major risk factor for respiratory tract and other systemic infections. Both active and passive cigarette smoke exposure increase the risk of infections. The morbidity and mortality of infectious diseases due to smoking are not widely appreciated by physicians. The mechanism of increased susceptibility to infections in smokers is multifactorial and includes alteration of the structural and immunologic host defenses. Lifetime smoking and other tobacco use almost always begins by the time kids graduate from high school [14]. Young kids' naïve experimentation frequently develops into regular smoking, which typically turns into a strong addiction. Every day more than 2,800 kids under 18 try smoking for the first time [15] fifth grade (ages 10 to 11 ), and 14.8 percent had tried smoking by the end of eighth grade. More than one-fourth $(28.7 \%)$ of twelfth grade students reported having used cigarettes by the end of tenth grade [16].

A 2013 nationwide survey found that nearly one in ten high school students $(9.3 \%)$ had smoked at least one whole cigarette before the age of 13 [17]. The 2014 nationwide Monitoring the Future Study reports that more than one out of every three twelfth grade students $(34.4 \%)$ and more than one out of every five tenth grade students $(22.6 \%)$ had ever tried smoking [18].

According to the National Survey on Drug Use and Health, more than 80 percent of all adult smokers begin smoking before the age of 18; and more than 90 percent do so before leaving their teens [19]. Every day 700 kids who have already experimented with cigarettes become new regular, daily smokers [20]. This is because nicotine is a highly addictive drug; and adolescents, who are still going through critical periods of growth and development, are particularly vulnerable to its effects [21]. Research on nicotine dependence shows that key symptoms of addiction-strong urges to smoke, anxiety, irritability and unsuccessful quit attempts - can appear in young kids within weeks or only days after occasional smoking first begins and well before daily smoking has even started [22]. According to a 2010 report prepared for the European Union by a group of distinguished scientists, tobacco has a substantially higher risk of causing addiction than heroin, cocaine, alcohol, or cannabis [23]. Overall, roughly one-third of all kids who become regular smokers before adulthood will eventually die from smoking [24]. If current trends continue, 5.6 million of the kids under 18 who are alive today will die from tobacco-related causes [25].

Evidence also shows that smoking can be a first step toward other substance abuse. Stopping or delaying that first step will reduce the risk that kids will progress to using other harmful substances [26]. Active cigarette smoking is one of the most important modifiable risk factors for coronary heart disease [2729]. Many epidemiologic studies [27-29] and reviews [30-36] have pointed to the effect of passive smoking on the risk of coronary heart disease. Several studies have suggested that the increased risk of coronary heart disease associated with passive smoking may be due to confounding effects of lifestyle and diet [37-38]. Passive smokers were more likely than nonsmokers to consume diets with fewer vegetables and fruits and more fat and were less likely to take antioxidant vitamin supplements [39-42].

Several mechanisms may increase the risk of coronary heart disease in persons exposed to environmental tobacco smoke. The acute effects of passive smoking include increases in the heart rate at rest, blood pressure, and blood levels of carboxyhemoglobin and carbon monoxide [43-44]. Other effects are an increase in the ratio of serum total cholesterol to high-density lipoprotein cholesterol, a decrease in the serum level of high-density lipoprotein cholesterol,[44] an increase in platelet aggregation, and endothelial-cell damage [45]. Abnormal platelet aggregation is an independent risk factor for coronary heart disease [30, 32, 33, 46]. There is also evidence that passive smoking may contribute to atherosclerosis 
by sensitizing neutrophils, causing their activation and subsequent oxidant-mediated tissue damage [47].

\section{CONCLUSION}

The high prevalence of passive smoking in the general population has implications for public health. To achieve a meaningful reduction in the burden to society of coronary heart disease, both passive and active cigarette smoking must be targeted. Many children are regularly exposed to cigarette smoke at home or in other environments, such as child-care facilities and schools. The only safe way to protect nonsmokers from exposure to cigarette smoke is to eliminate this health hazard from public places and workplaces, as well as from the home.

Future research should investigate how we can be more effective in lowering exposure, preventing smoking initiation, and facilitating smoking cessation.

\section{REFERENCES}

1. World Health Organization, \& Research for International Tobacco Control. (2008). WHO report on the global tobacco epidemic, 2008: the MPOWER package. World Health Organization.

2. Ezzati, M., \& Lopez, A. D. (2003). Estimates of global mortality attributable to smoking in 2000. The lancet, 362(9387), 847-852.

3. Gandini, S., Botteri, E., Iodice, S., Boniol, M., Lowenfels, A. B., Maisonneuve, P., \& Boyle, P. (2008). Tobacco smoking and cancer: a meta- analysis. International journal of cancer, 122(1), 155-164.

4. Giovannucci, E., Rimm, E. B., Stampfer, M. J., Colditz, G. A., Ascherio, A., Kearney, J., \& Willett, W. C. (1994). A prospective study of cigarette smoking and risk of colorectal adenoma and colorectal cancer in US men. JNCI: Journal of the National Cancer Institute, 86(3), 183-191.

5. Giovannucci, E., Rimm, E. B., Stampfer, M. J., Colditz, G. A., Ascherio, A., Kearney, J., \& Willett, W. C. (1994). A prospective stud

6. Heineman, E. F., Zahm, S. H., McLaughlin, J. K., \& Vaught, J. B. (1994). Increased risk of colorectal cancer among smokers: results of a 26- year follow- up of US veterans and a review. International journal of cancer, 59(6), 728738.

7. Pirkle, J. L., Flegal, K. M., Bernert, J. T., Brody, D. J., Etzel, R. A., \& Maurer, K. R. (1996). Exposure of the US population to environmental tobacco smoke: the Third National Health and Nutrition Examination Survey, 1988 to 1991. Jama, 275(16), 1233-1240.

8. Kiel, D. P., Zhang, Y., Hannan, M. T., Anderson, J. J., Baron, J. A., \& Felson, D. T. (1996). The effect of smoking at different life stages on bone mineral density in elderly men and women. Osteoporosis International, 6(3), 240-248.
9. Pryor, W. A. (1997). Cigarette smoke radicals and the role of free radicals in chemical carcinogenicity. Environmental health perspectives, 105(suppl 4), 875-882.

10. Rahman, I., \& MacNee, W. (1999). Lung glutathione and oxidative stress: implications in cigarette smoke-induced airway disease. American Journal of Physiology-Lung Cellular and Molecular Physiology, 277(6), L1067-L1088.

11. Federico, A., Morgillo, F., Tuccillo, C., Ciardiello, F., \& Loguercio, C. (2007). Chronic inflammation and oxidative stress in human carcinogenesis. International journal of cancer, 121(11), 2381-2386.

12. HERRERA, B., ÁlVAREZ, A. M., SÁNCHEZ, A., FERNÁNDEZ, M., RONCERO, C., BENITO, M., \& FABREGAT, I. (2001). Reactive oxygen species (ROS) mediates the mitochondrial- dependent apoptosis induced by transforming growth factor $B$ in fetal hepatocytes. The FASEB Journal, 15(3), 741-751.

13. Sihvo, E. I., Ruohtula, T., Auvinen, M. I., Koivistoinen, A., Harjula, A. L., \& Salo, J. A. (2003). Simultaneous progression of oxidative stress and angiogenesis in malignant transformation of Barrett esophagus. The Journal of thoracic and cardiovascular surgery, 126(6), 1952-1957.

14. Abuse, S. (2001). Health Services Administration. Results From the 2001 National Household Survey on Drug Abuse. Summary of National Findings.

15. Substance Abuse and Mental Health Services Administration. (2014). Results from the 2013 National Survey on Drug Use and Health: Summary of national findings. NSDUH Series $\mathrm{H}$ 48, HHS Publication No.(SMA) 14-4863, 1-143.

16. Johnston, L. D., O’Malley, P. M., \& Bachman, J. G. (2003). Monitoring the future: National results on adolescent drug use: Overview of key findings. Focus, 1(2), 213-234.

17. Eaton, D. K., Kann, L., Kinchen, S., Shanklin, S., Ross, J., Hawkins, J., ... \& Lim, C. (2010). Centers for Disease Control and Prevention (CDC) Youth risk behavior surveillance-United States, 2009. MMWR Surveill Summ, 59(5), 1-142.

18. Monitoring the Future Survey. (2014). See Table 1: Trends in Prevalence of Use of Cigarettes in Grades 8, 10, and 12.

19. SAMHSA. (2012). Calculated based on data in 2012 National Survey on Drug Use and Health.

20. Substance, A. (2014). Mental Health Services Administration (SAMHSA), HHS, Results from the 2013 National Survey on Drug Use and Health, NSDUH: Summary of National Findings.

21. HHS. (2012). The Health Consequences of Smoking-50 Years of Progress, A Report of the Surgeon General, 2014. "Preventing Tobacco Use Among Youth and Young Adults: A Report of the Surgeon General," 2012. 
22. Di Franza, J.R. (2000). "Initial Symptoms of Nicotine Dependence in Adolescents," Tobacco Control 9:313-19, September.

23. Scientific Committee on Emerging and Newly Identified Health Risks ("SCENIHR").(2010). Addictiveness and Attractiveness of Tobacco Additives.

24. Centers for Disease Control and Prevention (CDC. (1998). Incidence of initiation of cigarette smoking--United States, 1965-1996. MMWR. Morbidity and mortality weekly report,47(39), 837.

25. US Department of Health and Human Services. (2014). The health consequences of smoking- 50 years of progress: a report of the Surgeon General.

26. Johnson, P. B., Boles, S. M., \& Kleber, H. D. (2000). The relationship between adolescent smoking and drinking and likelihood estimates of illicit drug use. Journal of Addictive Diseases, 19(2), 75-81.

27. Doll, R., Peto, R., Wheatley, K., Gray, R., \& Sutherland, I. (1994). Mortality in relation to smoking: 40 years' observations on male British doctors. Bmj, 309(6959), 901-911.

28. USDHHS, U. (2006). Department of Health and Human Services. The Health Consequences of Involuntary Exposure to Tobacco Smoke: A Report of the Surgeon General.

29. Ockene, I. S., \& Miller, N. H. (1997). Cigarette smoking, cardiovascular disease, and stroke: a statement for healthcare professionals from the American Heart Association. Circulation, 96(9), 3243-3247.

30. Glantz, S. A., \& Parmley, W. W. (1991). Passive smoking and heart disease. Epidemiology, physiology, and biochemistry. Circulation, 83(1), $1-12$.

31. Steenland, K. (1992). Passive smoking and the risk of heart disease. Jama, 267(1), 94-99.

32. Wells, A. J. (1994). Passive smoking as a cause of heart disease. Journal of the American College of Cardiology, 24(2), 546-554.

33. Glantz, S. A., \& Parmley, W. W. (1995). Passive smoking and heart disease: mechanisms and risk. Jama, 273(13), 1047-1053.
34. Kritz, H., Schmid, P., \& Sinzinger, H. (1995). Passive smoking and cardiovascular risk. Archives of internal medicine, 155(18), 1942-1948.

35. Law, M. R., Morris, J. K., \& Wald, N. J. (1997). Environmental tobacco smoke exposure and ischaemic heart disease: an evaluation of the evidence. Bmj, 315(7114), 973-980.

36. Wells, A.J. (1998). Heart disease from passive smoking in the workplace. J Am Coll Cardiol, 31:1-9.

37. Denson, K.W.E. (1996). Smoke in the face, diet, and harm to the heart. Lancet, 348:1663-4.

38. Aronow, W.S.(1978). Effect of passive smoking on angina pectoris. N Engl J Med, 299:21-4.

39. Sidney, S., Caan, B.J., Friedman, G.D. (1989). Dietary intake of carotene in nonsmokers with and without passive smoking at home. Am J Epidemiol, 129:1305-9.

40. Thornton, A., Lee, P., Fry, J. (1994). Differences between smokers, ex-smokers,passive smokers and non-smokers. J Clin Epidemiol, 47:1143-62.

41. Matanoski, G., Kanchanaraksa, S., Lantry, D., Chang, Y. (1995). Characteristics of nonsmoking women in NHANES I and NHANES I epidemiologic followup study with exposure to spouses who smoke. Am J Epidemiol, 142:149-57.

42. Osler, M. (1998). The food intake of smokers and nonsmokers: the role of partner's smoking behavior. Prev Med, 27:438-43.

43. Khalfen, E.S., Klochkov, V.A. (1987). Effect of passive smoking on the physical tolerance of ischemic heart disease patients. Ter Arkh, 59:1125.

44. Feldman, J., Shenker, I.R., Etzel, R.A. (1991). Passive smoking alters lipid profiles in adolescents. Pediatrics, 88:259-64.

45. Davis, J.W., Shelton, L., Watanabe, I.S., Arnold, J. (1989). Passive smoking affects endothelium and platelets. Arch Intern Med, 149:386-9.

46. Lam, J.Y., Latour, J.G., Lesperance, J., Waters, D. (1994). Platelet aggregation, coronary artery disease progression and future coronary events. Am J Cardiol, 73:333-8.

47. Anderson, R., Theron, A.J., Richards, G.A., Myer, M.S., van Rensburg, A.J. (1991). Passive smoking by humans sensitizes circulating neutrophils. Am Rev RespirDis; 144:570-4. 